\title{
La Masonería en Portugal en el siglo XVIII^
}

\section{A. H. DE OLIVEIRA MARQUÉS Universidade Nova de Lisboa}

La introducción de la masonería en Portugal se remonta al segundo cuarto del siglo XVIII, no muy distante de la fecha oficial de su nacimiento en Londres.

Tal vez fuera fundada en 1727 por comerciantes británicos residentes en Lisboa una logia que fue registrada por la Inquisición como de los "herejes mercaderes", por ser protestantes casi todos sus miembros. Esta logia se regularizó en 1735 al afiliarse con la Gran Logia de Londres donde obtuvo, primero, el número de registro 135, y, después, el 120. Sólo en 1755 fue borrada del cuadro de las logias de presidencia londinense, aunque probablemente no funcionase desde mucho tiempo atrás. La Inquisición no la incomodó, debido a la nacionalidad y a la homogeneidad profesional de sus miembros, protegidos por los tratados con Inglaterra.

En 1733 se fundó una segunda logia en Lisboa, denominada "Casa Real dos pedreiros-livres de Lusitanian. Sus obreros eran ahora predominantemente católicos. Conocemos los nombres, nacionalidades y profesiones de muchos de ellos, quizás la mayoría. Se trata sobre todo de irlandeses, tanto comerciantes como mercenarios en el ejército portugués, pero había también gentes de mar, médicos, tres padres dominicos, un mesonero, un peluquero y hasta un maestro de danza. El Hermano de esta logia que vendría a ser más famoso fue el húngaro Carlos Mardel, oficial del ejército mercenario y arquitecto de nombre, a quien tanto debe Lisboa, En 1738, al ser publicada la bula condenatoria de la masonería por el papa Clemente XII, la logia se disolvió, pero algunos de los obreros, especialmente los protestantes, no acataron la decisión papal, ingresando en la otra logia.

* Conferencia pronunciada en la Facultad de Filosofía y Letras de Cádiz en 1987, traducida del portugués al español por Manuel Bustos Rodríguez. 
La tercera logia creada en tierra portuguesa tuvo un destino más trágico. Fue fundada en 1741 en Lisboa por el tallista de diamantes John Coustos, nacido en Suiza, pero nacionalizado posteriormente inglés. Duró cerca de dos años, ingresando en la misma una treintena de extranjeros residentes en Portugal, la mayoría franceses, junto a algunos ingleses, un belga súbdito del Imperio, un holandés y un italiano. Casi todos eran católicos, aunque Coustos, el Venerable, era protestante, y algunos pocos como él. En cuanto a profesiones, prácticamente todos estaban ligados al comercio, con un elevado porcentaje de negociantes y tallistas de piedras preciosas, oro y plata.

Denunciados a la Inquisición en 1743, los masones de la logia de Coustos fueron apresados, torturados y sentenciados, siendo el Venerable y los dos vigilantes condenados a varios años de destierro y servicio en las galeras. Gracias a la intervención de algunos extranjeros, quizás masones, fueron liberados al cabo de algún tiempo con la condición de salir del país. Coustos volvió a Inglaterra, escribiendo y publicando posteriormente unas famosas memorias, aún hoy una de las mejores fuentes para el conocimiento de las trágicas condiciones del proceso inquisitorial.

La persecución de 1743 desmanteló este primer esbozo de organización masónica en tierra portuguesa. La propia logia de los «herejes mercaderes» vio restringidas sus actividades, hasta "abatir columnas» de todo. La masonería sólo volverá a tomar fuerza en la década de 1760-1770 gracias a la mayor tolerancia gubernamental. El marqués de Pombal dejó a los "pedreiros-livres" en paz, al mismo tiempo que limaba las garras de la Inquisición y la convertía en dócil instrumento del poder estatal. El último «Regimento" de la Inquisición, que data de 1774, no incluía la práctica masónica entre los crímenes denunciables y punibles, ni siquiera se refería a ella, lo que representaba un enorme paso adelante en el camino de la tolerancia estatal y eclesiástica.

No sabemos con certeza si Pombal fue o no iniciado masón. Hombre iluminado y extranjerizante, una entrada suya en la Orden podría deberse a motivos varios, no necesariamente a una convicción masónica profunda. Moda, convivencia, promoción social, curiosidad y muchas otras cosas le llevarían a solicitar su filiación y a verse aceptado. Si fue iniciado, sin embargo, debió hacerlo en Londres (1739-1744) o en Viena (1745-1748), durante su período como diplomático, a sabiendas que en esta última ciudad convivió íntimamente con masones, visitando según algunos testimonios la logia vienesa "Aux Tros Canons». Recordemos que Pombal fue igualmente aceptado como miembro de la prestigiosa "Royal Society of London" (1740) — sin que con ello tengamos que con- 
siderarlo como científico de ningún tipo- $y$, anteriormente (1733), se convirtió en socio de la Real Academia de Historia de Lisboa.

De vuelta a la patria, se ignora todo sobre el seguimiento de cualquier actividad másonica por parte del futuro marqués, aunque corriese la fama de su iniciación. También es verdad que las fuentes se muestran especialmente poco abundantes sobre este período de la historia de la masonería en Portugal, no siendo de extrañar que el propio ministro las hiciese destruir para que no quedasen huellas de su conducta y de la de amigos y colaboradores suyos. De lo que no parece caber duda es de la ausencia de persecusiones contra los "pedreiros-livres", en contraste con los procedimientos anteriores a 1750 y posteriores a 1777. Excepción hecha de los encarcelamientos en la isla de Madeira, que se pueden explicar más por el celo de su gobernador - celo no corroborado por las autoridades de Lisboa- que por las instrucciones recibidas del poder central, la masonería fue dejada en libertad o, al menos, tolerada. Hecho bien extraño este, si recordamos los despóticos procedimientos habitualmente seguidos por la administración pombalina, su rigurosa censura, su omnipresente policía y su "nueva» Inquisición estatalizada.

De los ministros del gobierno pombalino existen testimonios de haber sido masones o simpatizantes de la masonería el secretario de Estado de los Negocios Extranjeros y de la Guerra (1757-1775) don Luis de Cunha Manuel, y el secretario de Estado de Marina y Ultramar (1770-1795) Martinho de Melo e Castro.

Otros elementos, escogidos al azar por una investigación no sistemática y mucho menos exhaustiva, pueden confirmar la relativa libertad y popularidad de que gozó la masonería durante el gobierno pombalino. Así, en el techo de una de las salas del Palacio Pombal, en Oeiras, la figura de los tres hermanos abrazados - Sebastiāo José de Carvalho e Melo, Francisco Xavier de Mendonça y Paulo de Carvalho de Mendonça- tienen una evidente connotación masónica, bien en la leyenda (Concordia fratrum), bien en los motivos alegóricos que la rodean. También en el pedestal de la estatua ecuestre a don José, erigida en Lisboa en el Terreiro do Paço, se puede ver una de las figuras sosteniendo un compás y una escuadra, junto a otras alegorías masónicamente interpretables. No se trata, como es obvio, de signos masónicos claros, ni era creíble que ellos se mostrasen en el Portugal, ferozmente preconceptuado, del tercer cuarto del siglo XVIII. Pero son indicios, posibilidades, a corroborar lo que arriba dejamos indicado.

En cuanto a logias, hay noticias de unas tres en Lisboa a partir de la década de 1760: una de ingleses, otra de franceses y una tercera mixta en que entraban civiles y militares, posiblemente también con portugueses. Además de Lisboa, fue fundada una logia de militares en Elvas o 
en Olivença y otra en Funchal, ambas por influencia extranjera. La estancia del conde de Lippe en Portugal (1762-1764, 1767-1768), masón él mismo, acompañado de varios oficiales también masones, tuvo un considerable impacto en la difusión del ideal y de la práctica de la masonería, singularmente en los ambientes militares.

Con el gobierno de María I, volverán las persecuciones. Aunque no discriminados directamente como tales, los "pedreiros-livres» fueron asociados con los herejes, ateos, descreídos, libertinos y otras varias designaciones que el "establishment" de entonces juzgaba peligrosas y condenables. Sobre todo a partir del estallido de la Rèvolución Francesa, los masones caerán bajo la vigilancia policial, siendo considerados elementos difusores de las ideologías subversivas del estado absoluto y clerical.

Luego, en 1778, se volvió a la práctica de los autos de fe. En el de 11 de octubre de dicho año, saldrán en Lisboa, por herejía y descreimiento, diez personas, casi todas ellas militares o ligadas al famoso Sexto Regimiento de Artillería de Oporto, acuartelado en Valença. La lista incluía científicos de renombre, tales como José Anastaçio da Cunha, pero el único individuo inculpado como masón (entre otras muchas culpas) era el sargento mayor y médico Miguel Kinseslach (Kincelao), mercenario holandés de 57 años, entre cuyas actividades se contaba el soborno de "varias personas para entrar en la secta de los pedreiros-livres", en la cual se hallaba hacía muchos años.

Sólo a partir de 1791, sin embargo, se desencadenó la gran persecución contra la masonería portuguesa, la segunda de su corta historia, en la que se dieron la mano Intendencia General de Policía e Inquisición. En otoño de dicho año comenzarán los encarcelamientos sistemáticos y los interrogatorios en Lisboa. En febrero de 1792, un Edicto del Santo Oficio añadía a los crímenes previstos por el "Regimento" de 1774, una lista de nuevos delitos denunciables por todos los buenos cristianos en el plazo de treinta días. El antepenúltimo Item rezaba: «Se sabe y oye que algunas personas hacen o por cualquier modo concurren para hacerse ayuntamientos, agregaciones o conventículos intitulados De liberi Muratori o franc-maçons, vulgo Pedreiros-livres, o con cualquier otro título, conforme a la variedad de los idiomas», penalizándose también (penúltimo Item) la compra, venta, posesión o lectura de libros o escritos con ellos relacionados.

El edicto de 1792 fue poco a poco publicado en todo el país, siendo leído en las iglesias. En Madeira llegó a comienzos de abril, haciéndose público en Funchal el día 10 de dicho mes. Luego lloverán las denuncias y las autodenuncias, especialmente en la isla, tierra más pequeña que Lisboa y en la que todos se conocían. Encontramos por entonces una vein- 
tena de procesos relativos a la capital, al tiempo que, en Madeira, según el "Relatorio" del Comisario del Santo Oficio, las denuncias fueron nada menos que cincuenta y siete, y las autodenuncias cincuenta y dos. Varias personas decidieron incluso huir de Portugal y domiciliarse en el extranjero. Este fue el caso de nueve masones madeirenses, tres de ellos acompañados por toda la familia, que salieron ocultamente del puerto de Funchal en abril de 1792 en un navío perteneciente a dos de ellos, refugiándose en los Estados Unidos de América.

Las persecuciones de 1791-1792 desmantelaron por segunda vez la organización masónica portuguesa. Tanto en Lisboa como en Funchal y alrededores, los hermanos fueron encarcelados, impidiéndoseles el continuar sus reuniones, Las logias tuvieron que «abatir columnas» y esperar días mejores, pero ello no impidió el esporádico funcionamiento de algunas, como sucedió en Coimbra en 1793-1794.

Tracemos ahora un cuadro más pormenorizado de la organización de la masonería portuguesa en este período. Las fuentes son particularmente abundantes para Lisboa y Madeira, y serán estas dos zonas sobre las que más nos extendamos.

Hacia 1790-1791 había en Lisboa, al menos, una logia de ciudadanos portugueses, aunque posiblemente fúesen dos o más. No contaban con un lugar fijo de reunión, lo que nos dificulta un conocimiento exacto, pareciéndonos a veces estar en presencia de tres o cuatro logias cuando en realidad se trataría de una o dos itinerantes. Las reuniones tenían lugar en sitios muy variados, y hay noticias de sesiones "en los Arciprestes" (parroquia de Santa Engracia), en la calle de los Algibebes (parroquia de la Magdalena), en plena "Baixa» lisboeta, en una quinta en Marvila o en el Pozo del Obispo, etc.

En cuanto al número de obreros por logia, se nos presentan dudas. La conjugación de varias pesquisas permite identificar más de una veintena de participantes en una logia activa en 1790-1791. De esa veintena, la mayoría $(36,4 \%)$ eran oficiales del ejército y de la marina, seguidos por los comerciantes $(22,7 \%)$, los clérigos $(18,2 \%)$, los funcionarios públicos $(9,1 \%)$ y un propietario. Diríase que se trata de una composición plenamente burguesa, confirmando todo aquello que ya sospechábamos. Con todo, se sabe por otras fuentes que numerosos representantes de la nobleza, incluso de la alta, habían ingresado en la masonería, llegándose hasta el punto de incluir a la persona del.príncipe Da Beira, el malogrado don José (†1788) como iniciado e incluso "protector». ¿Pertenecerían esos nobles a una o más de una logias especiales? ¿Se abstendrían de participar en las reuniones, siendo por ello desconocidos por los masones comunes? ¿O serían sus nombres cuidadosamente omitidos en los autos 
del Santo Oficio por los propios inquisidores? La verdad es que tenemos que esperar hasta el período de las invasiones francesas para encontrarnos con una logia lisboeta de composición social heterogénea, con miembros de la alta nobleza, del alto clero, la burguesía y el pueblo.

Por la misma época había en Madeira al menos dos grandes logias, y quizás una tercera. Al igual que en Lisboa, las reuniones se realizaban en casas particulares, generalmente en quintas apartadas del centro de Funchal. Conocemos casi a la perfección la estructura interna de ambas, con un total de 68 obreros $(36+32)$. Al igual que en el continente predominaba la oficialidad militar, pero en segundo lugar estaban los propietarios rurales (muchos de ellos titulares de mayorazgos), proporcionando a las logias madeirenses el tonus hidalgo que en Lisboa no encontraban. Venían en tercer lugar los clérigos, y después los funcionarios públicos y los comerciantes, con porcentajes iguales. Estos cinco grupos se equilibraban bastante. Había aun, cón porcentajes inferiores, médicos, farmacéuticos, abogados, profesores y estudiantes. Por otra parte, la masonería de Madeira sobrepasaba en mucho el número arriba referido, situándose su contingente total entre cien y ciento cincuenta iniciados (ciento treinta y tres, según una estimación oficial del Santo Oficio de 14 de junio de 1792, siendo veintiocho de ellos ausentes), un $0,17-0,20 \%$ de la población del archipiélago (unas 75.000 personas). Era un porcentaje muy elevado que revela la rápida "masonización» de Madeira, porcentaje que nunca fue posible conseguir en el continente, incluso durante el apogeo de la masonería portuguesa en 1913-1914.

Puede preguntarse quiénes eran los masones de entonces, qué impacto ejercieron en su tiempo y qué proyección histórica tuvieron. La mayoría, como siempre, no dejaron huellas ni se distinguieron por su actividad. Pero quedarán nombres altisonantes que importa recordar: miembros de la nobleza, como el duque de Lafões, el marqués de Nisa (don Domingo Xavier de Lima), el conde de Linhares (don Rodrigo de Sousa Coutinho), el conde de Mafra (don Lorenzo Xavier de Lima), el conde de Subserra (Manuel Martins Pamploma), y los Morgados de Assentiz y de Mateus; clérigos, como don Frei Alejandro de la Sagrada Familia (obispo de Malaca y de Angola), don Frei Francisco de San Luis y João María Soares Castelo Branco; políticos y diplomáticos como João Paulo Bezerra, Francisco José de Brito, Pedro de Melo Breyner, Inocencio de Miranda y Manuel Ignacio da Costa Quintela; hombres de ciencia, como Brotero, Francisco Antonio de Ciera, José Anastaçio da Cunha, Melo Franco, Manuel do Espírito Santo Limpo, João Francisco de Oliveira, Manuel Henriques de Paiva, José Antonio da Rosa, el abad Correia da Serra y Domingo Vamdelli; literatos, como Bocage, Filinto Elisio, Morais y Francisco Alvares de Nóbrega ("el pequeño Camoens"); 
juristas, como Francisco Duarte Coelho, Domingos Monteiro de Alburquerque, José Diego de Mascarenhas Neto, Sebastiāo de Sampaio, António Ribeiro dos Santos y Fernando Luis Pereira de Sousa; capitalistas, y hombres de negocios, como el Barón de Quintela; Anselmo da Cruz Sobral y Joaquín Ignacio da Cruz Sobral: son elementos bastantes como para probar que la masonería portuguesa, a pesar de hallarse aún en sus comienzos, estaba ya suficientemente diseminada entre todos los grupos sociales y profesionales, ejerciendo su influencia en un vasto haz de actividades profanas. Muchos de estos hombres habían sido iniciados en el extranjero, y su "comparticipación" masónica era escasa en tierra portuguesa. Otros, finalizada la iniciación, nunca trabajaban en logia, confinando su labor y su convivencia masónica a sus palacios, locales de trabajo y círculos de amigos. Otros, incluso, se limitaban a tomar parte en los banquetes. No olvidemos que pertenecer a la masonería tenía entonces mucho de moda y de afirmación de virilidad, sin implicar necesariamente convicciones profundas de otra naturaleza.

Las logias masónicas portuguesas eran independientes. Esto quiere decir que no estaban ligadas entre sí por ningún vínculo administrativo, ni participaban conjuntamente en ninguna actividad. El Gran Oriente Lusitano, como federación de las logias portuguesas, sólo surgirá en 1803. Unicamente la logia de ingleses fundada en Lisboa en torno a 1727 se afiliará ("regularizará» en terminología masónica) en seguida a la Gran Logia de Londres, pero será "abatida al cuadro respectivo» en 1755 por haber cesado sus actividades.

Existían, no obstante, lazos de solidaridad entre los miembros de varias oficinas y entre ellos y los masones extranjeros. En Madeira, los contactos entre los hermanos de las dos o tres logias eran frecuentes, porque todos se conocían y convivían en el mundo profano. Es probable que lo mismo pasara en Lisboa entre los masones portugueses y los de las logias extranjeras. Y, aunque se sepa aún poco a este respecto, hay indicios de que había algún contacto entre obreros de distintos estratos sociales; como nos lo deja entrever el texto masónico de 1791 con que concluiremos esta conferencia.

En cuanto a relaciones con el extranjero, éstas existían igualmente. La estancia en Portugal y el impacto en la masonería portuguesa de masones oriundos de Inglaterra, el Imperio alemán y Francia, muchos de ellos pertenecientes a la alta nobleza, abrió las puertas a estos contactos que el tiempo incrementaría. En 1773 hay noticias de haber participado en un banquete solemne del Gran Oriente de Francia, en París, el masón portugués don José de Noronha, futuro juez de la India y de Mina. Algunos obreros de las logias madeirenses habían sido iniciados en Boston, incluso antes de la independencia de los Estados Unidos, y mantu- 
vieron sus relaciones con la casa madre en los años siguientes. El navío madeirense que en 1791 huía hacia América, izó al entrar en el puerto de Boston una bandera con símbolos masónicos, lo que le valió inmediata protección y auxilio en aquella ciudad. Por lo que respecta al ritual, no hay noticia de haberse practicado en las logias portuguesas con anterioridad a 1797 más que los tres grados simbólicos de Aprendiz, Compañero y Maestro. En Madeira, Jean Josset d'Orquigny, un médico francés a quien se debió buena parte de la expansión masónica en la isla, quiso introducir grados superiores según una escala y un ritual que él mismo inventara, pero que no dio resultado. La práctica ritualista seguida en Portugal, ya en tiempos de Juan V, se aproximaba considerablemente a la que aún hoy existe en cualquier masonería simbólica, lo que comprueba el mantenimiento de la esencia del ritual en doscientos cincuenta años de trabajo. Aún se revela su carácter cristiano (y católico en las logias de portugueses y extranjeros de religión católica), con juramento sobre la Biblia, invocaciones religiosas, oraciones, etc., lo que explica la adhesión de numerosos sacerdotes y la afirmación, constantemente reiterada, en las pesquisas de los inquisidores, de que nada se practicaba en las logias que fuese contrario a la fe. Se revela también el respeto formal para con las instituciones monárquicas y el orden social establecido. No existen noticias de que en las logias se conspirase ni que las mismas, en sus trabajos cotidianos, ejerciesen acción subversiva alguna. Las logias se limitaban a actos de beneficencia general, a socorrer a los hermanos necesitados y a preocuparse por la curación de los enfermos, a organizar ágapes de convivencia, a iniciar nuevos obreros y a promover a los ya iniciados a los grados de Compañeros y Maestros; y poco más.

El «peligro» de la masonería no estaba en su organización formal y ritualista, y tanto inquisidores como policías se engañaban completamente al suponer que los trabajos de logia escondían secretos terribles, atentatorios contra el Trono y el Altar. El "peligro", estaba, eso sí, en el espiritu masónico, con sus principios de tolerancia, de convivencia social y de edades, de superación de preconceptos, de igualdad y de fraternidad.

Con el desembarco en Lisboa de un cuerpo expedicionario inglés en junio de 1797 - en el cuadro de la guerra con Francia - se introducirán las condiciones para que la orden masónica se reorganizase. Luego, en 1798, había constituidas unas cuatro logias inglesas en Lisboa, tres de ellas ligadas a regimientos militares, y una cuarta que aceptaba a civiles y ciudadanos portugueses. Todas ellas estaban afiliadas a la Gran Logia dé Londres, recibiendo los números 94, 112, 179 y 315. Esta última tuvo para la historia de la masonería portuguesa propiamente di- 
cha un papel relevante por ser considerada años después como la logia número uno, cuando se comenzaron a dar números a las oficinas nacionales. Fue la logia "União».

Hasta 1803 se crearon otras logias, y, al lado de ellas, muchos masones y simpatizantes fueron ganando diversas ciudades y villas del país. Pero su historia no tiene cabida ya en los propósitos de la presente conferencia y por eso no las desarrollamos.

En uno de los procesos de la Inquisición encontramos un texto masónico de gran interés, que pensamos es el primer texto masónico portugués, aunque ciertamente influido por documentos extranjeros similares. Se trata de un discurso para ser pronunciado por el "orador" de una logia (uno de los cargos existentes en cualquier oficina de los tres primeros grados) en el acto de ingreso de un nuevo Obrero: Vamos a leerlo íntegramente, y con su lectura, tan evocadora del período que nos reunió hoy, daremos por terminada nuestra contribución:

"¿Quién nos lo iba a decir, masones, que os ibáis a encontrar en una sociedad de honra y de virtud? Esta Sociedad tan antigua como los hombres ha sido vista por los mismos hombres con ojos fascinantes, aplicándoles ideas, unas exóticas, otras criminales, todas aéreas y pocas verdaderas. Yo no pretendo haceros un discurso pomposo en vuestra augusta recepción. Entre nosotros reina siempre la simplicidad y la moderación. Unicamente voy a exponeros vuestras obligaciones, que acabáis de contraer.

$Y$ la primera es aquella impuesta a todo el hombre, de conservar un corazón incorrupto, apartado de los vicios, al margen de las funestas pasiones y adornado de las virtudes que inspira la Razón y la Humanidad. Esto significa vuestra entrada desnudados de todos los "metales", vestidos sólo de las virtudes. La segunda, una particular obediencia y fidelidad al Rey, a la Patria, según el legítimo Poder y Gobierno al que fuéreis súbditos. Esta es la voluntad e imperturbable obligación de los masones, puesto que él es por su profesión, un hombre de caridad, de unión y de virtud social, que sin obediencia al poder soberano del Príncipe no sería más que un rebelde insocial y un cismático de la unión y de la verdadera Masonería que sólo quiere unión, paz y obediencia legítima. La tercera obligación es la de socorrer a vuestros hermanos en sus necesidades, hermanos que os fuesen conocidos por un examen maduro y exacto. $\mathrm{Y}$ es por esto que contrajísteis la cuarta obligación, de no revelar vuestro secreto que consiste en las señales, palabras y toques que se os tiene enseñados por cuanto, revelados ellos, nos veríamos incomodados de infinitos hermanos, apócrifos y necesita- 
dos, y vendría una Sociedad tan virtuosa y útil a desvanecerse y a profanarse.

Ved aquí lo que vinísteis a buscar. Ved aquí nuestros secretos. Y si teméis otras ideas de esta Augusta sociedad, conoced ahora lo que es el mundo y lo que es el pueblo, siempre ansioso de saber lo que ignora. Aplica todo lo que hay de más extravagante al objeto que no conoce. Entre nosotros, lo que hay más agradable, además de contar con tantos hermanos como masones hay, es la igualdad que se observa y que se simboliza en el Nivel. Luis XIV, Federico y Ganganelli tenían entre nosotros el mismo lugar que cualquier otro. A la mesa, tenían la misma obediencia. Cantaban si les mandaban y bebían a la salud que se les proponía con la misma alegría sin soberanía ni distinción. Todos somos iguales y, como entre nosotros es acautelado e incluso prohibido tratar de materias que no sean puramente masónicas, y menos de religión o de Estado, está a la vista porque reconocemos por hermanos cualesquier masones del mundo, con tal que no sean ateos. Porque éstos, si es que los puede haber, no podrán entrar en Sociedad de virtudes como ésta, pues no pueden ser fieles, ni tener caridad, ni sistema alguno social y de humanidad. Ellos no pueden jurar por un Dios en que no creen. No pueden por eso mismo tener obediencia al príncipe que tiene el poder de Dios. Y no pueden finalmente figurar en la Sociedad sino contradiciéndose. Otro cualquier hombre, sin embargo, puede entrar en nuestra Sociedad con tal que practique sus obligaciones, que como acabáis de oír, son comunes a todos los hombres de cualquier Estado o religión que sean.

$\mathrm{Y}$ en pocas palabras os he dicho todo lo esencial de la Masonería. El resto, son todo accidentes, de grados y significaciones que embellecen pero que no mudan la sustancia. Por eso oiréis hablar del grado de Maestro, Compañero, etc., que no son más que adiciones de más brillante ornato y distinción, y que algunos hechos célebres de la historia les dieron origen, pero que todo converge en ser el Masón un hombre honrado y hermano verdadero de sus hermanos.

Dije.". 